\title{
The crucial role of hydrocarbons in the formation of gold and uranium ore in the Witwatersrand Basin, South Africa
}

SEBASTIAN H FUCHS ${ }^{1}$, DIRK SCHUMANN ${ }^{2}$, ROBERT F MARTIN $^{3}$ AND MARTIN COUILLARD ${ }^{4}$

${ }^{1}$ Federal Institute for Geosciences and Natural Resources

${ }^{2}$ Fibics Incorporated

${ }^{3}$ McGill University

${ }^{4}$ National Research Council Canada

Presenting Author: Sebastian.fuchs@bgr.de

The Witwatersrand is the world's largest repository of gold, but it also represents a prime example of a classical sedimentary basin, in which hydrocarbon production and alteration occurred alongside the formation of ore. In many ore horizons, so-called "reefs", a spatial correlation exists between the presence of hydrocarbons and high-grade mineralization. The burial of biomass, likely derived from the first organisms on the young Earth, accumulated in the clastic sediments and generated oil and hydrocarbon gases that were able to liberate and react with detrital minerals (e.g. uraninite) within the succession. Postdepositional regional metamorphism promoted the development and the basin-wide circulation of hydrothermal fluids $\left(\sim 350^{\circ} \mathrm{C}\right.$ at peak metamorphism). These had the capacity to mobilize substantial amounts of gold over a large distance. The thermal and chemical interaction between the hydrocarbons and hydrothermal solutions occurred when the (aqueous) fluids entered the reef. Oil-in-water micro-emulsions were the result. The hot hydrothermal fluids in turn promoted the progressive thermal breakdown and fractionation of oil into high volumes of carbonic gases (e.g. methane) and a pyrobitumen residue. These interaction processes and their consequences for mineralization for gold and uranium minerals have been intensively studied and will be illustrated during the talk.

Scanning and transmission electron microscopy analyses in combination with geochemical modeling reveal that the precipitation of gold in Witwatersrand was triggered by the micro-emulsions. The hydrocarbons drastically lowered the solubility of dissolved gold, which led to precipitation onto reactive hydrocarbon surfaces. The ongoing release of carbonic gases into the sediments away from their source resulted in the deposition of gold even at a considerable distance from visible pyrobitumen. Microtextural and mineralogical observations show that the oils in turn reacted with detrital uraninite in sediments en route, dissolved uranium and other trace metals, and redeposited aggregates of the uraninite nanoparticles during thermal alteration of the oils. The special geological conditions in Witwatersrand basin permitting the interaction between hydrothermal solutions and hydrocarbons created a highly efficient natural ore-forming "factory". 